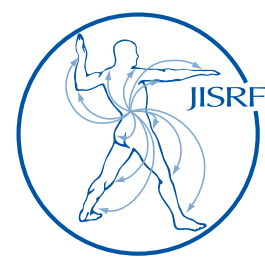

Check for updates

\title{
Comparison of Functional Outcomes of Total Knee Arthroplasty Using Two Different Single Radius Implants
}

Pourmoghaddam $A^{1}$, Dettmer $M^{1}$, Malanka $S^{1}$, Kreuzer $S^{1}$

\begin{abstract}
Total knee arthroplasty is used as the treatment plan for patients with end-stage osteoarthrosis associated with severely affected function. Although TKA has been used for many years, some patients have reported overall dissatisfaction regarding the outcome. This may be due to the complexity of the joint design. In recent years, the concept of single-radius knee prosthetics is gaining more popularity as many studies have discussed biomechanical and clinical benefits of such design compared to traditionally used multi-radius implants. In this study, we report the outcome of 78 patients who were treated by TKA utilizing a relatively new single-radius implant, Unity. Results showed that all subjects reported good outcomes as expressed by significant improvement in their Knee Injury and Osteoarthritis Outcome Scores at 1-year post-operative. The symptom, pain, and ADL subscores demonstrated significant improvement in patients with scores twice the pre-operative value, while the average improvement in sport and quality of life subscores showed even greater improvement with scores three times the pre-operative value.
\end{abstract}

Keywords: total knee arthroplasty, Unity implant, single radius

Level of Evidence: AAOS Therapeutic Level III

\section{Introduction}

Total Knee arthroplasty (TKA) is the ultimate treatment to alleviate the symptoms of the knee osteoarthritis (OA) after alternative treatments are exhausted. TKA is used to relieve the pain and to restore normal function of the knee. However, different implants and surgical approaches have shown inconsistent results with achieving normal function of the knee. The limitations in performing normal activities such as limited range of motion, less stability of the knee compared to normal knee, and the loss of proprioception may be factors affecting the outcome of the
1 Amir Pourmoghaddam, PhD; Marius Dettmer, PhD; Stefany JK Malanka BSc.; Stefan W. Kreuzer, MD MSc.

The University of Texas Health Science Center at Houston, 7000 Fannin, Suite 1200, Houston, Texas 77030 USA

(Direct reprint requests to Marius Dettmer)

(C) 2016 Pourmoghaddam, Dettmer, Malanka, Kreuzer. All rights reserved. Authors retain copyright and grant the journal right of first publication with the work. Reconstructive Review follows the Creative Commons Attribution-NonCommercial CC BY-NC. This license allows anyone to download works, build upon the material, and share them with others for non-commercial purposes as long as they credit the senior author, Reconstructive Review, and the Joint Implant Surgery \& Research Foundation (JISRF). An example credit would be: "Courtesy of (senior author's name), Reconstructive Review, JISRF, Chagrin Falls, Ohio". 
surgery. Therefore, design of knee implants has been the center of attention for TKA. While most common knee designs on the market are based on multiple centers of rotation, a new concept was proposed in 1993 based on a single-radius design to achieve more natural knee kinematics [1]. Since then, many studies have demonstrated that during a flexion-extension activity, knee rotation follows a single radius curvature path over the femoral condyles by rotating around a fixed transepicondylar axis [2-6]. A single-radius design concept provides a longer extensor moment arm and retains the movement isometry throughout the full range of motion $[7,8]$. Therefore, single radius design knees are expected to retain more natural kinematics of movement during daily activities [9-11]. Previous studies have reported superior functional outcomes in patients who received single-radius knee implants. These outcomes include a better rehabilitation process, faster recovery and return- to-work-time, and significant reduction in knee pain. In theory, the aforementioned benefits would result in superior patient satisfaction level [9-11]. The Unity Total Knee System, like other single radius knee designs, has been designed to reduce the muscular activities of the knee extensors and to provide better ligament stability, which may ultimately result in reduced and more normal patellar load $[12,13]$. This implant maintains the medial joint axis throughout full range of motion. This design concept helps with isometry of MCL loading and movement after TKA [14].

In a very recent study by Paszicsnyek, clinical outcomes of 89 patients treated by TKA using Unity knee implants with a posterior stabilizing approach (PS) were evaluated [14]. The authors indicated positive survivorship, clinical and performance improvements, and no radiographic failure. The Posterior cruciate ligament (PCL) is known to stabilize the knee during flexion, particularly by constraining the femoral and tibia relative translation, and in high flexion by constraining the mediolateral translation of tibia. Therefore, it has been suggested that PCL preservation might retain the natural knee movement after TKA [15]. In this study we aimed to add more clinical data to the body of the literature and to analyze the functional improvements in patients with Unity Knee TKA by using a cruciate retaining $(\mathrm{CR})$ method. We hypothesized that the functional outcomes measured by the Knee Injury and Osteoarthritis Outcome Score (KOOS) evaluation would demonstrate significant improvement in patients during the postoperative period. In addition, we aimed to report revision and negative cases and to discuss the potential effects of patients' demographics on the outcome of TKA using the Unity TKA system.

\section{Materials and Methods}

A retrospective review of preoperative and postoperative data of 80 individuals (34 males/46 females) who received total knee arthroplasty treatment was conducted. All patients received the Unity single radius Total Knee System (Corin Ltd., Cirencester, UK). The demographics of patients are shown in Table 1 . However, as the majority of the patients (total 78) were treated by using a cruciate retaining method (32 males/46 females) the demographics of the patients used in the study is reported in Table 2. The data were collected from January 2013 to May 2015 at a single institution from cases performed by one of the authors. The data were collected by using an online webbased data-entry software from an IRB-approved joint registry. Informed consent was obtained from all participants in the study prior to data collection.

Table 1-Demographics of CR patients in the study.

\begin{tabular}{|l|c|c|c|c|c|}
\hline & $\mathbf{N}$ & Minimum & Maximum & Mean & Std. Deviation \\
\hline $\begin{array}{l}\text { Height } \\
(\mathrm{cm})\end{array}$ & 78 & 149.86 & 193.04 & 170.72 & 9.40 \\
\hline $\begin{array}{l}\text { Weight } \\
(\mathrm{kg})\end{array}$ & 78 & 52 & 147.70 & 87.01 & 19.68 \\
\hline BMI & 78 & 21 & 45.50 & 29.69 & 5.53 \\
\hline $\begin{array}{l}\text { Age } \\
\text { (years) }\end{array}$ & 78 & 53 & 85 & 68.47 & 7.23 \\
\hline
\end{tabular}

A standard medial parapatellar approach was performed and all patients received a cemented single-radius cruciate-retaining Unity ${ }^{\mathrm{TM}}$ Total Knee System (Corin Ltd., Cirencester, UK). The sequence of surgical steps included a distal cut using an intramedullary reference guide followed by the proximal tibial cut. The slope and the varus/valgus angle was adjusted to the natural tibial plateaus of the patient avoid to exceed the accepted range of $+/-3$ degrees. The extension gap was then balanced by soft tissue release. Femoral rotation was adjusted using the EquiBalanceTM in 90 degrees of flexion as shown in Figure 1.

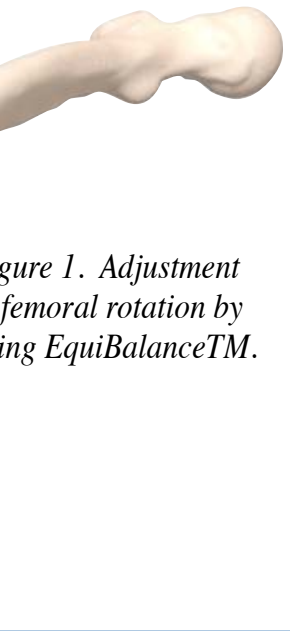


The knee cap was measured pre-cut and was resurfaced to reestablish pre-operative thickness. Once adequate hemostasis was obtained, the joint was copiously irrigated followed by cementing of the tibia, patella and femoral component. All excess cement was removed and followed by irrigation and closure in layers. The design of this total knee system utilizes a single radius implant geometry with an instrument platform which aims to maintain the medial joint-line throughout range of motion in order to optimize MCL isometry post TKA. In addition, the patellofemoral track in this design has a lower profile and an early lateralized anatomic patellar track compared with traditional knee systems, which reduces constraint on the patellofemoral mechanism and therefore minimizes anterior knee pain [16]. The goal of this TKR system is to maintain balance throughout the range of motion, resulting in improved patient outcomes.

The underlying causes for a primary total knee arthroplasty were end-stage osteoarthritis $(n=76 ; 97.43 \%)$, posttraumatic arthritis $(n=1 ; 1.23 \%)$ or a failed implant $(n=1$; $1.13 \%$ ). Each patient completed at least one postoperative questionnaire to calculate the clinical outcomes represented by KOOS. The KOOS represents five subscores which were compared for each group. These postoperative data were collected either during the follow-up clinic visits or by using an online questionnaire.

Patients in this study received an implant by Corin (Unity Knee, Corin, UK). The five subscores were Symptom, Pain, ADL, Sport, and Quality of Life (QOL). A postoperative radiograph was used in each case to check for fixation, component failure or malalignment, and progressive radiolucency around the implant.

\section{Statistical Model}

A Multivariate mixed model was utilized to compare the postoperative outcome of each implant. A significance level of .05 was assumed in this study. Body Mass Index (BMI) and age (as covariates) and gender (as between group factor) were utilized in the model to evaluate potential changes in functional outcome in response to changes in these factors. All statistical analyses were conducted using SPSS 23.0.0 (SPSS Inc., Chicago, Illinois, USA).

\section{Results}

All patients in the study completed at least one postoperative questionnaire to allow the calculation of KOOS for functional outcome measurement. The results of the overall multivariate mixed model indicated that the overall functional outcomes significantly improved between the preoperative and post-operative survey with $(\mathrm{F}(5,73)=77.34$, $\mathrm{p}<0.001)$ ). This improvement in functional outcome was significant for all subscores, as summarized in Table 2. The post-surgery subscores were significantly higher in all patients demonstrating excellent clinical performance improvement.

Table 2 - Comparison of pre and postoperative

\begin{tabular}{|c|c|c|c|c|}
\hline \multicolumn{2}{|c|}{ KOOS } & Mean Square & F (1,78) & Significance \\
\hline \multirow{2}{*}{$\begin{array}{c}\text { Pre } \\
\text { vs. } \\
\text { Post }\end{array}$} & Symptom & 47251.44 & 201.77 & $<.001$ \\
\cline { 2 - 5 } & Pain & 75372.06 & 375.36 & $<.001$ \\
\cline { 2 - 5 } & ADL & 61960.78 & 315.40 & $<.001$ \\
\cline { 2 - 5 } & Sport & 79470.78 & 230.49 & $<.001$ \\
\cline { 2 - 5 } & QOL & 81743.85 & 230.40 & $<.001$ \\
\hline
\end{tabular}

Table 3 - KOOS subscores assessed during preoperative and postoperative surveys.

\begin{tabular}{|l|c|c|c|c|}
\hline & \multicolumn{5}{|c|}{ PreOp } \\
\hline KOOS & Minimum & Maximum & Mean & Std. Deviation \\
\hline Symptom & 0 & 97 & 47.78 & 20.91 \\
\hline Pain & 0 & 84 & 42.26 & 16.75 \\
\hline ADL & 5 & 95 & 46.31 & 17.56 \\
\hline Sport & 0 & 95 & 19.67 & 18.02 \\
\hline QOL & 0 & 57 & 22.19 & 15.51 \\
\hline & \multicolumn{5}{|c|}{ PostOp } \\
\hline KOOS & Minimum & Maximum & Mean & Std. Deviation \\
\hline Symptom & 43 & 100 & 82.59 & 13.96 \\
\hline Pain & 45 & 100 & 86.22 & 13.94 \\
\hline ADL & 33 & 100 & 86.17 & 14.85 \\
\hline Sport & 0 & 100 & 64.81 & 24.22 \\
\hline QOL & 0 & 100 & 67.97 & 23.48 \\
\hline
\end{tabular}

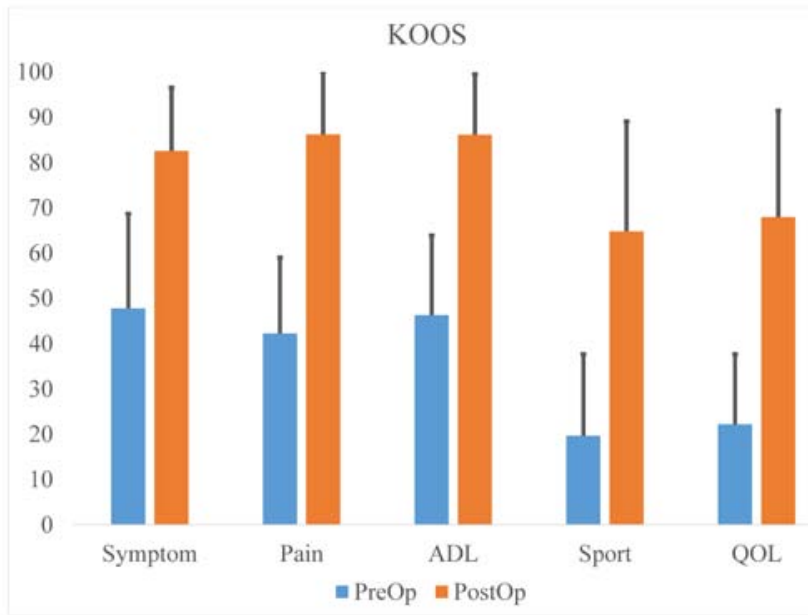

Figure 2- The KOOS scores comparison between Preoperative and Postoperative period. 
Table 4-KOOS subscores for categorized based on gender.

\begin{tabular}{|c|c|c|c|c|c|c|c|c|c|c|c|}
\hline \multirow[t]{2}{*}{ KOOS } & \multirow[t]{2}{*}{ Gender } & \multicolumn{5}{|c|}{ Average } & \multicolumn{5}{|c|}{ Standard Error } \\
\hline & & Symptom & Pain & ADL & Sport & QOL & Symptom & Pain & ADL & Sport & QOL \\
\hline \multirow[t]{2}{*}{ PreOp } & $\mathrm{F}$ & 43.39 & 37.43 & 40.84 & 15.23 & 19.34 & 3.16 & 2.41 & 2.28 & 2.47 & 2.33 \\
\hline & $\mathrm{M}$ & 54.09 & 49.18 & 54.15 & 26.03 & 26.28 & 3.30 & 2.64 & 3.11 & 3.19 & 2.54 \\
\hline \multirow[t]{2}{*}{ PostOp } & F & 80.06 & 84.28 & 85.58 & 62.04 & 66.52 & 2.15 & 2.16 & 2.27 & 4.55 & 3.39 \\
\hline & M & 86.21 & 89.00 & 87.00 & 68.78 & 70.06 & 2.18 & 2.21 & 2.52 & 3.39 & 4.30 \\
\hline
\end{tabular}

In addition, the results of the mixed model that was conducted to evaluate the differences between demographics data indicated that patients' demographics were not significant predictors of the functional outcome. For BMI $(\mathrm{F}(5,70)=1.06, \mathrm{p}=0.39)$ and the KOOS subscores are summarized in Table 4 , for age $F(5,70)=0.565$, $p=0.658$ and for gender effects $\mathrm{F}(5,70)=2.124 \mathrm{p}=0.073$.

\section{Discussion}

Although TKA has been utilized as the ultimate treatment method for end-stage osteoarthritis and despite high survivorship of this procedure, for many patients it has not always resulted in satisfactory functional outcomes. Many studies indicated dissatisfaction of up to $20 \%$ of patients from the surgery [17-20] attributed mainly to the significant changes in knee kinematics that may result in abnormal gait and balance experience [21]. It has been proposed that prosthesis design is the primary factor altering the function of the knee following TKA [7,18,22-25]. As a result, implant manufacturers have focused on developing prosthetic knee devices that simulate the natural knee kinematics.

Traditionally, knee prosthetics with multi-radius design over the femoral component have been used; however, recent development of single-radius knee implants have shown improvements in both mechanical and clinical functions of the knee after TKA $[8,13,14,18,26-30]$. In these implants, the biomechanical functions are improved by lengthening the extensor moment arm, providing longer distal and posterior axis, and by maintaining the isometry of the rotation and force distribution throughout the range of motion resulting in less patellar load [7,8, 31,32]. The mechanical improvements of the prosthetic knee after TKA therefore may contribute to better functional outcomes, decreased knee pain, a shorter rehabilitation period, faster recovery and reduction in the time to return to work $[18,29,30,33]$.

We report on the short term clinical outcome of a newly designed and recently released to the market single-radius implant, Unity Total Knee System. Our results indicat- ed significant improvements in all clinical outcomes of the first 78 CR patients in a single surgeon series. Our results are similar to those recently reported by Paszicsnyek indicating good survivorship and positive clinical outcome of this implant [14]. In that study, the author investigated the functional outcome of the TKA by using Unity and indicated significant improvement in the outcomes measured by American Knee Society Score, Oxford Knee score and radiographic measurements. However, the authors had not reported KOOS subscores in that study.

Molt et. al have reported the clinical outcomes measured by KOOS in patients who received a traditional single radius implant, Triathlon TKA (Stryker, Mahwah, New Jersey, USA). In our study the average follow-up range was $361 \pm 228$ days. Therefore, we descriptively compared our results with those 1-year results reported by Molt et. al., as summarized and reproduced in Table 4 and depicted in Figure 3. The scores in the current study are comparatively higher than those of patients who were treated by Triathlon CR in the earlier study [34]. Further research including a randomized controlled study is needed to compare the clinical outcomes of these single-radius implants.

Table 5 - KOOS subscores reported by Molt et. al versus those reported in the current study.

\begin{tabular}{|c|c|c|c|c|c|}
\hline & & \multicolumn{2}{|c|}{ PreOp } & \multicolumn{2}{c|}{ 1 year PostOp } \\
\hline KOOS & & Mean & Std. Deviation & Mean & Std. Deviation \\
\hline Pain & Unity & 42.26 & 16.75 & 86.22 & 13.94 \\
\hline & Triathlon CR & 43 & 19 & 80 & 19 \\
\hline & & & & & \\
\hline Symptom & Unity & 47.78 & 20.91 & 82.59 & 13.96 \\
\hline & Triathlon CR & 52 & 20 & 76 & 15 \\
\hline & & & & & \\
\hline ADL & Unity & 46.31 & 17.56 & 86.17 & 14.85 \\
\hline & Triathlon CR & 45 & 15 & 79 & 20 \\
\hline & & & & & \\
\hline Sport & Unity & 19.67 & 18.02 & 64.81 & 24.22 \\
\hline & Triathlon CR & 12 & 13 & 38 & 24 \\
\hline & & & & & \\
\hline QOL & Unity & 22.19 & 15.51 & 67.97 & 23.48 \\
\hline & Triathlon CR & 25 & 15 & 68 & 25 \\
\hline
\end{tabular}




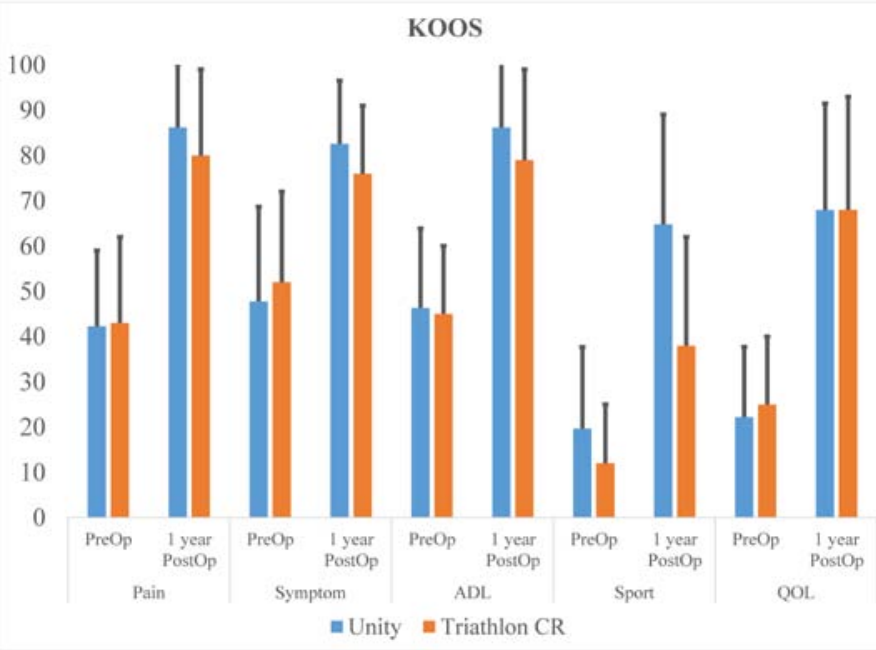

Figure 3 - KOOS subscores reported by Molt et all for patients treated by two types of single-radius Knee (Triathlon CR) compared to the KOOS subscores reported in the current study for patients receiving Unity.

There are several limitations to the current study. First, the study was conducted retrospectively on single design implants. The aim of the study was to evaluate the improvement in patients' functional scores; however, future studies may be needed to further evaluate the outcome of the Unity implant compared to other traditionally available single-radius prosthetics prospectively. The surgeries were conducted by one surgeon; thus, this might limit the scope and generalizability of the outcome. Future studies may be designed to use multiple investigational centers. In addition, we did not analyze the range of motion or conduct other biomechanical assessments of the performance, which should be considered for future studies; however, clinical assessments based upon patient- reported outcomes, as assessed by the application of KOOS, can be a reliable indicator of post-operative improvement and potentially overall patient satisfaction.

\section{Conclusion}

In this study we reported the short term clinical outcome of a new single-radius knee prosthetic design. Patients in the study demonstrated excellent improvement in functional outcome indicating the short term success of this implant design. Future studies and longer-term data collection is needed to further generalize the outcome of this study.

\section{Disclosure}

The authors declare that there is no conflict of interest regarding the publication of this paper. For full disclosures refer to last page of this journal.

\section{References}

1. Hollister, A. M., Jatana, S., Singh, A. K., Sullivan, W. W., \& Lupichuk, A. G. (1993). The axes of rotation of the knee. Clinical Orthopaedics and Related Research, (290), 259-68. Retrieved from http://www.ncbi.nlm.nih.gov/ pubmed/8472457

2. Blakeney, W. G., Khan, R. J. K., \& Wall, S. J. (2011). Computer-assisted techniques versus conventional guides for component alignment in total knee arthroplasty: a randomized controlled trial. The Journal of Bone and Joint Surgery. American Volume, 93(15), 1377-84. http://dx.doi.org/10.2106/JBJS.I.01321

3. Churchill, D. L., Incavo, S. J., Johnson, C. C., \& Beynnon, B. D. (1998). The transepicondylar axis approximates the optimal flexion axis of the knee. Clinical Orthopaedics and Related Research, (356), 111-8. Retrieved from http://www.ncbi. nlm.nih.gov/pubmed/9917674

4. Insall, J. N., Lachiewicz, P. F., \& Burstein, A. H. (1982). The posterior stabilized condylar prosthesis: a modification of the total condylar design. Two to four-year clinical experience. The Journal of Bone and Joint Surgery. American Volume, 64(9), 1317-23. Retrieved from http://www.ncbi.nlm.nih.gov/pubmed/7142239

5. Mugnai, R., Digennaro, V., Ensini, A., Leardini, A., \& Catani, F. (2014). Can TKA design affect the clinical outcome? Comparison between two guided-motion systems. Knee Surgery, Sports Traumatology, Arthroscopy : Official Journal of the ESSKA, 22(3), 581-9. http://doi.org/10.1007//00167-013-2509-9

6. Tayot, O., Ait Si Selmi, T., \& Neyret, P. (2001). Results at 11.5 years of a series of 376 posterior stabilized HLS1 total knee replacements. Survivorship analysis, and risk factors for failure. The Knee, 8(3), 195-205. Retrieved from http://www.ncbi. nlm.nih.gov/pubmed/11706727

7. Ezechieli, M., Dietzek, J., Becher, C., Ettinger, M., Calliess, T., Ostermeier, S., \& Windhagen, H. (2012). The influence of a single-radius-design on the knee stability. Technology and Health Care : Official Journal of the European Society for Engineering and Medicine, 20(6), 527-34. http://dx.doi.org/10.3233/THC-2012$\underline{0698}$

8. Jenny, J.-Y. Y., Miehlke, R., Saragaglia, D., Geyer, R., Mercier, N., Schoenahl, J.Y. Y., \& Thiel, B. (2013). Single-radius, multidirectional total knee replacement. Knee Surgery, Sports Traumatology, Arthroscopy : Official Journal of the ESSKA, 21(12), 2764-2769. http://dx.doi.org/10.1007/s00167-012-2178-0

9. Daniilidis, K., \& Tibesku, C. O. (2013). Frontal plane alignment after total knee arthroplasty using patient-specific instruments. International Orthopaedics, 37(1), 45-50. http://dx.doi.org/10.1007/s00264-012-1732-1

10. Harvie, P., Sloan, K., \& Beaver, R. J. (2011). Three-Dimensional Component Alignment and Functional Outcome in Computer-Navigated Total Knee Arthroplasty. The Journal of Arthroplasty, 26(8), 1285-1290. http://dx.doi.org/10.1016/j. arth.2010.12.022

11. Ng, V. Y., DeClaire, J. H., Berend, K. R., Gulick, B. C., \& Lombardi, A. V. (2012). Improved accuracy of alignment with patient-specific positioning guides compared with manual instrumentation in TKA. Clinical Orthopaedics and Related Research, 470(1), 99-107. http://doi.org/10.1007/s11999-011-1996-6

12. Hall, J., Copp, S. N., Adelson, W. S., D'Lima, D. D., \& Colwell, C. W. (2008). Extensor Mechanism Function in Single-Radius Vs Multiradius Femoral Components for Total Knee Arthroplasty. Journal of Arthroplasty, 23(2), 216-219. http:// doi.org/10.1016/j.arth.2007.04.001

13. Wang, H., Simpson, K. J., Ferrara, M. S., Chamnongkich, S., Kinsey, T., \& Mahoney, O. M. (2006). Biomechanical differences exhibited during sit-to-stand between total knee arthroplasty designs of varying radii. The Journal of Arthroplasty, 21(8), 1193-9. http://doi.org/10.1016/j.arth.2006.02.172

14. Paszicsnyek, T. (2015). Early Experience With a Modern Generation Knee System: Average 2 Years' Follow-Up. Reconstructive Review, 5(4), 23-28.

15. Mihalko, W. M., \& Krackow, K. a. (1999). Posterior cruciate ligament effects on the flexion space in total knee arthroplasty. Clinical Orthopaedics and Related Research, (360), 243-250.

16. Abolghasemian, M., Samiezadeh, S., Sternheim, A., Bougherara, H., Barnes, C. L., \& Backstein, D. J. (2014). Effect of patellar thickness on knee flexion in total knee arthroplasty: A biomechanical and experimental study. Journal of Arthroplasty, 29(1), 80-84. http://doi.org/10.1016/j.arth.2013.04.026

17. Bourne, R. B., Chesworth, B. M., Davis, A. M., Mahomed, N. N., \& Charron, K. D. (2010). Patient satisfaction after total knee arthroplasty: who is satisfied and who is not? Clinical Orthopaedics and Related Research, 468, 57-63. http://doi. org/10.1007/s11999-009-1119-9 
18. Harwin, S. F., Issa, K., Given, K., Hitt, K. D., Greene, K. A., Pivec, R., ... Mont, M. A. (2013). Clinical and patient-reported outcomes of primary TKA with a single-radius design. Orthopedics, 36(7), e877-82. http://doi.org/10.3928/0147744720130624-17

19. Mahomed, N., Gandhi, R., Daltroy, L., \& Katz, J. N. (2011). The Self-Administered Patient Satisfaction Scale for Primary Hip and Knee Arthroplasty. Arthritis, 2011, 1-6. http://doi.org/10.1155/2011/591253

20. Scott, C. E. H., Howie, C. R., MacDonald, D., \& Biant, L. C. (2010). Predicting dissatisfaction following total knee replacement: a prospective study of 1217 patients. The Journal of Bone and Joint Surgery. British Volume, 92(9), 1253-8. http://doi.org/10.1302/0301-620X.92B9.24394

21. Bell, S. W., Young, P., Drury, C., Smith, J., Anthony, I., Jones, B., ... McLean, A. (2014). Component rotational alignment in unexplained painful primary total knee arthroplasty. Knee, 21(1), 272-277. http://doi.org/10.1016/j.knee.2012.09.011

22. Cook, L. E., Klika, A. K., Szubski, C. R., Rosneck, J., Molloy, R., \& Barsoum, W. K. (2012). Functional outcomes used to compare single radius and multiradius of curvature designs in total knee arthroplasty. The Journal of Knee Surgery, 25(3), 249-53. Retrieved from http://www.ncbi.nlm.nih.gov/pubmed/23057145

23. Harman, M. K., Banks, S. A., Kirschner, S., \& Lützner, J. (2012). Prosthesis alignment affects axial rotation motion after total knee replacement: a prospective in vivo study combining computed tomography and fluoroscopic evaluations. BMC Musculoskeletal Disorders, 13, 206. http://doi.org/10.1186/1471-2474-13-206

24. Harvie, P., Larkin, J., Scaddan, M., Longstaff, L. M., Sloan, K., \& Beaver, R. J. (2013). Stiffness after total knee arthroplasty: does component alignment differ in knees requiring manipulation? A retrospective cohort study of 281 patients. The Journal of Arthroplasty, 28(1), 14-9. http://doi.org/10.1016/j.arth.2012.03.003

25. Huang, N. F. R., Dowsey, M. M., Ee, E., Stoney, J. D., Babazadeh, S., Choong, P. F., ... P.F., C. (2012). Coronal Alignment Correlates With Outcome After Total Knee Arthroplasty. Five-Year Follow-Up of a Randomized Controlled Trial. Journal of Arthroplasty, 27(9), 1737-1741. http://doi.org/10.1016/j.arth.2012.03.058
26. Kim, D.-H., Kim, D.-K., Lee, S.-H., Kim, K.-I., \& Bae, D.-K. (2015). Is Single-Radius Design Better for Quadriceps Recovery in Total Knee Arthroplasty? Knee Surgery \& Related Research, 27(4), 240-6. http://doi.org/10.5792/ ksrr.2015.27.4.240

27. Liu, S., Long, H., Zhang, Y., Ma, B., \& Li, Z. (2015). Meta-Analysis of Outcomes of a Single-Radius Versus Multi-Radius Femoral Design in Total Knee Arthroplasty. The Journal of Arthroplasty, 1-9. http://doi.org/10.1016/j.arth.2015.10.017

28. Mahoney, O. M., \& Kinsey, T. L. (2008). 5- to 9-year survivorship of single-radius, posterior-stabilized TKA. Clin Orthop Relat Res, 466(2), 436-442. http://doi. org/10.1007/s11999-007-0070-X

29. Mahoney, O. M., McClung, C. D., dela Rosa, M. a., \& Schmalzried, T. P. (2002), The effect of total knee arthroplasty design on extensor mechanism function. The Journal of Arthroplasty, 17(4), 416-421. http://doi.org/10.1054/arth.2002.32168

30. Wang, H., Simpson, K. J., Chamnongkich, S., Kinsey, T., \& Mahoney, O. M. (2005). A biomechanical comparison between the single-axis and multi-axis total knee arthroplasty systems for the stand-to-sit movement. Clinical Biomechanics, 20(4), 428-433. http://doi.org/10.1016/j.clinbiomech.2004.12.003

31. D'Lima, D. D., Poole, C., Chadha, H., Hermida, J. C., Mahar, A., \& Colwell, C. W (2001). Quadriceps moment arm and quadriceps forces after total knee arthroplasty. Clinical Orthopaedics and Related Research, (392), 213-20. Retrieved from http://www.ncbi.nlm.nih.gov/pubmed/11716385

32. Ostermeier, S., \& Stukenborg-Colsman, C. (2011). Quadriceps force after TKA with femoral single radius. Acta Orthopaedica, 82(3), 339-343. http://doi.org/10. 3109/17453674.2011.574564

33. Harwin, S. F., Greene, K. A., \& Hitt, K. (2008). Triathlon total knee arthroplasty: 4-year outcomes with a high-performance implant. The Journal of Knee Surgery, 21(4), 320-6. Retrieved from http://www.ncbi.nlm.nih.gov/pubmed/18979936

34. Molt, M., \& Toksvig-Larsen, S. (2014). Similar early migration when comparing CR and PS in Triathlon ${ }^{\mathrm{TM}}$ TKA: A prospective randomised RSA trial. Knee, 21(5), 949-954. http://doi.org/10.1016/j.knee.2014.05.012

\section{Tissue Sparing Total Hip Arthroplasty Study Group}

The Joint Implant Surgery and Research Foundation has a long history in the study of THA. It began back in 1971 when Professor Charles O. Bechtol, M.D. established JISRF as a nonprofit scientific and educational foundation.

JISRF continues this study with the formation of a new study group of international surgeons and scientists. Findings will be posted on the foundation's web site at www.jisrf.org.

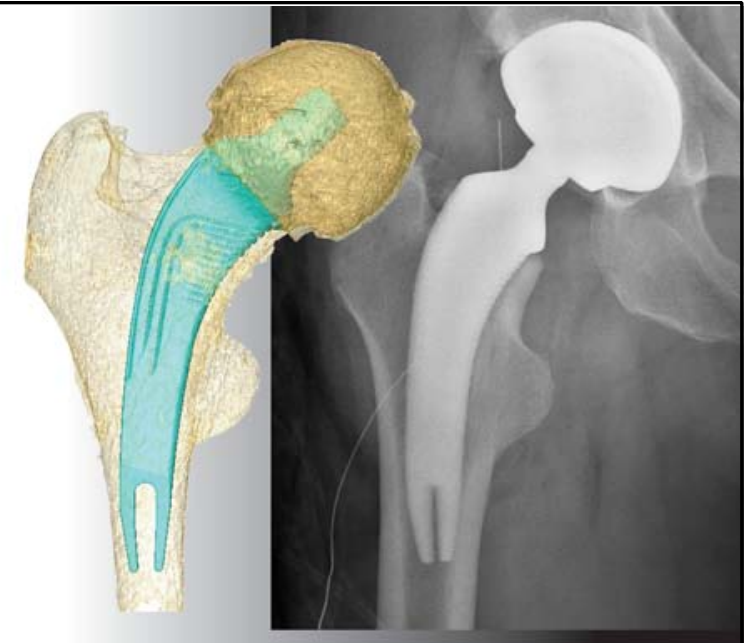

Joint Implant Surgery and Research Foundation 46 Chagrin Shopping Plaza, \#117 • Chagrin Falls, OH 44022

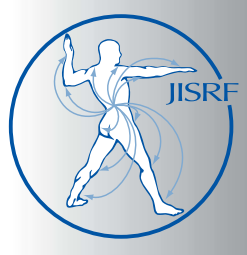

Surgeons interested

in learning more

contact the

Executive Director at www.JISRF.org 